07,16

\title{
Зависимость механических свойств сорбентов от размеров нанопор
}

\section{() А.С. Колесникова}

Саратовский национальный исследовательский государственный университет им. Н.Г. Чернышевского, Саратов, Россия

E-mail: Kolesnikova.88@mail.ru

\section{(Поступила в Редакцию 25 октября 2016 г.)}

Рассмотрено влияние размера нанопор на механические свойства пористого углеродного материала плотностью $1.4 \mathrm{~g} / \mathrm{cm}^{3}$. Построены атомистические модели пористых углеродных материалов с разным размером нанопор. Численные эксперименты осуществлялись с использованием молекулярно-механического метода, основанного на потенциале Бреннера. Выявлены численные значения модулей Юнга пористых углеродных структур при определенных значениях нанопор. Установлено, что при увеличении размера нанопор модуль Юнга изменяется в сторону уменьшения.

Работа выполнена при финансовой поддержке Президентской стипендии 2016-2018 гг. (проект № СП-2502.2016.1).

DOI: 10.21883/FTT.2017.07.44593.399

\section{1. Введение}

Пористые углеродные материалы (ПУМ) используются в различных областях медицины, науки и техники. В настоящее время к таким областям относятся сорбционная медицина и фармацевтика, электроника и энергетика. В медицине ПУМ (сорбенты) привлекают к себе большое внимание благодаря их пористости. Например, микропористые структуры используются для удаления из биологических жидкостей продуктов небольшой молекулярной массы. В настоящее время известны разнообразные пористые углеродные микро- и наноструктуры [1-6]. Плотность таких структур колеблется от 0.26 до $2.2 \mathrm{~g} / \mathrm{cm}^{3}$ [2].

К одной из форм ПУМ относится стеклоуглерод. Структура стеклоуглерода состоит из многослойных графеновых чешуек или графитовых хлопьев, расположенных случайным образом (нанометровые фуллереноподобные сфероиды и неупорядоченный многослойный 3D-графен) [7-11]. В работе [12] показано, что на плотность и свойства стеклоуглерода оказывает влияние термообработка. Чем выше температура обработки, тем ниже плотность структуры. В [13] с помощью метода конечных элементов показано, что с увеличением пористости сорбентных структур модуль Юнга уменьшается. Однако при этом не учитывалось атомарное строение данных структур, а также плотность материала, т.е. не установлено изменение плотности при уменьшении размеров пор.

На данный момент в литературе не представлено работ, посвященных исследованию влияния размера нанопор на механические свойства материала, которые наиболее важны для использования ПУМ в качестве сорбента. В [14] экспериментально и теоретически показано, что модуль Юнга стеклоуглерода с плотно- стью $1.4 \mathrm{~g} / \mathrm{cm}^{3}$ составляет $30 \mathrm{GPa}$ при размере нанопор $15-20 \mathrm{~nm}$. При этом в [15-17] показано, что в процессе пиролиза можно управлять размерами пор стеклоуглерода. В связи с этим в настоящей работе впервые проведено теоретическое исследование изменения модуля Юнга ПУМ плотностью $1.4 \mathrm{~g} / \mathrm{cm}^{3}$ в зависимости от размера пор. Исследование осуществлялось с использованием энергетического потенциала Бреннера [18] с учетом периодических граничных условий. Вычисления проводились в программном пакете Ring [19]. Апробация реализации потенциала Бреннера в программном пакете Ring представлена в работе [20].

\section{2. Методы}

Получение ПУМ с размерами пор от микро- до нанопор в зависимости от температуры, при которой осуществляется испарение полифурфурилового спирта, реализуется в процессе пиролиза [15-17].

Для теоретического исследования изменения модуля Юнга стеклоуглерода с плотностью $1.4 \mathrm{~g} / \mathrm{cm}^{3}$ в зависимости от размера нанопор были построены три атомистические модели пористых углеродных наноструктур (см. рисунок): для первой модели размер нанопор составлял $0.4-0.8 \mathrm{~nm}$; для второй $-0.2-1.12 \mathrm{~nm}$; для третьей $-0.7-1.3 \mathrm{~nm}$.

Количество атомов в элементарной ячейке составляло 1899. Элементарная ячейка атомистического ПУМ имела размер $3 \times 3 \times 3 \mathrm{~nm}$.

Для расчета модуля Юнга была использована методика, включающая следующие этапы.

1. Расчет полной энергии равновесной конфигурации моделей ПУМ с помощью эмпирического потенциала Бреннера [18]. 


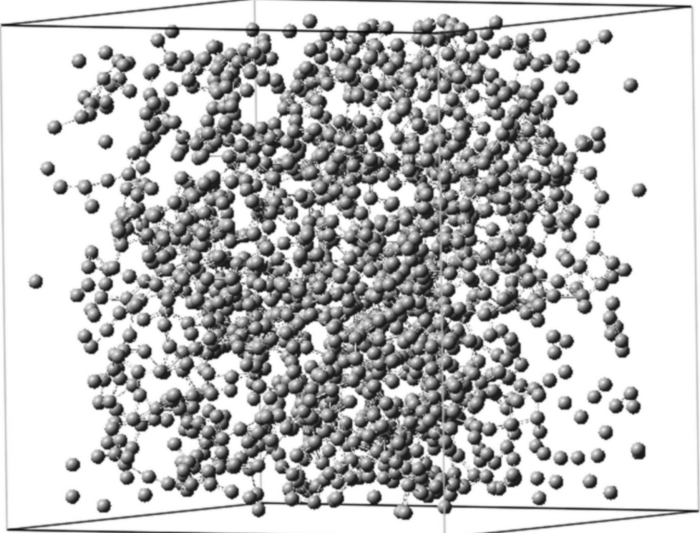

$b$

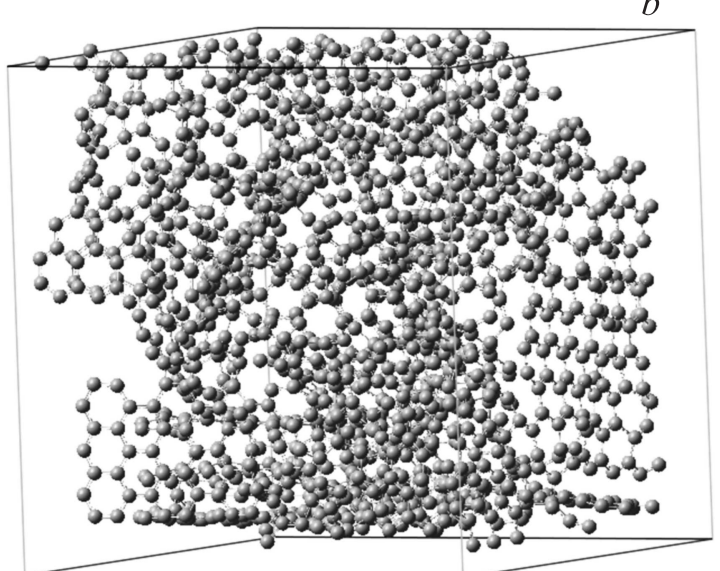

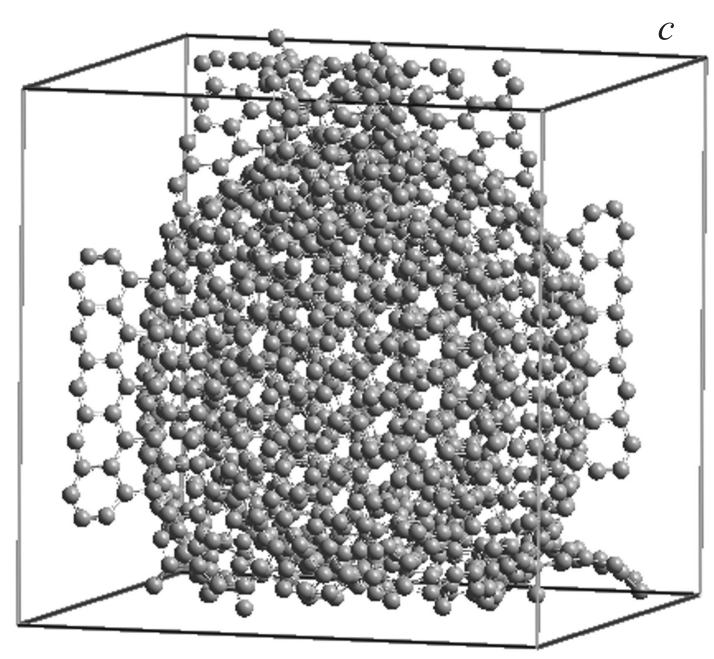

Пористые углеродные наноструктуры. $a$ - размер пор от 0.4 до $0.8 \mathrm{~nm}, b-$ размер пор от 0.2 до $1.12 \mathrm{~nm}, c-$ paзмер пор от 0.7 до $1.3 \mathrm{~nm}$.

2. Расчет изменения энергии наноструктуры при деформации, которая определяется в свою очередь тензором деформации. Для такого расчета использовалась следующая схема.

- Минимизация полной энергии наноструктуры по координатам. Полученная оптимизированная геометрия соответствует недеформированному состоянию структуры, которое описывается тензором деформации, заданным единичной матрицей третьего порядка.

- Расчет энергии деформированной структуры, определяемой тензором деформации $\varepsilon$

$$
\varepsilon=\left(\begin{array}{lll}
\varepsilon_{11} & \varepsilon_{12} & \varepsilon_{13} \\
\varepsilon_{21} & \varepsilon_{22} & \varepsilon_{23} \\
\varepsilon_{31} & \varepsilon_{32} & \varepsilon_{33}
\end{array}\right)
$$

3. Расчет упругих постоянных по формуле [21]

$$
C_{i j k l}=\frac{1}{V_{0}} \frac{\partial^{2} E(\varepsilon)}{\partial \varepsilon_{i j} \partial \varepsilon_{k l}}
$$

где $V_{0}$ - объем ячейки, $E(\varepsilon)-$ полная энергия структуры, определяющаяся тензором деформации, $\varepsilon_{i j}, \varepsilon_{k l}-$ компоненты матрицы тензора деформации. Дифференцирование в соответствии с описанной выше процедурой вычисления энергии осуществлялось численно.

Для индексации упругих постоянных применялась нотация Фойгта. При расчете модуля Юнга использовались две компоненты тензора деформации, располагающиеся на главной диагонали. Эти компоненты определяют плоскость, вдоль которой осуществлялась деформация. Если в качестве компоненты тензора деформации выбрать, например, $\varepsilon_{i j}, \varepsilon_{k l}$, то упругие постоянные будут определяться следующим образом:

$$
\begin{aligned}
& C_{11}=\frac{1}{V_{0}} \frac{\partial^{2} E(\varepsilon)}{\partial \varepsilon_{11} \partial \varepsilon_{11}}, \\
& C_{12}=\frac{1}{V_{0}} \frac{\partial^{2} E(\varepsilon)}{\partial \varepsilon_{11} \partial \varepsilon_{22}} .
\end{aligned}
$$

4. Расчет модуля Юнга $Y$ с помощью упругих постоянных осуществляется по формуле [22]

$$
Y=\frac{\left(C_{11}-C_{12}\right) /\left(C_{11}+2 C_{12}\right)}{C_{11}+C_{12}}
$$


Размеры нанопор и значения модуля Юнга ПУМ

\begin{tabular}{c|c|c}
\hline Плоскость & $\begin{array}{c}\text { Размер } \\
\text { нанопор, } \mathrm{nm}\end{array}$ & $\begin{array}{c}\text { Значение } \\
\text { модуля Юнга, } \mathrm{GPa}\end{array}$ \\
\hline$x y$ & $0.4-0.8$ & 1495 \\
$y z$ & $0.4-0.8$ & 1451 \\
$x z$ & $0.4-0.8$ & 1495 \\
$x y$ & $0.2-1.12$ & 732 \\
$y z$ & $0.2-1.12$ & 754 \\
$x z$ & $0.2-1.12$ & 773 \\
$x y$ & $0.7-1.3$ & 661 \\
$y z$ & $0.7-1.3$ & 675 \\
$x z$ & $0.7-1.3$ & 640
\end{tabular}

\section{3. Результаты и их обсуждение}

Для построения элементарной ячейки модели пористой углеродной структуры с размером нанопор $0.4-0.8 \mathrm{~nm}$ в кубический объем размером $3 \times 3 \times 3 \mathrm{~nm}$ помещались хаотично расположенные атомы углерода.

Для построения элементарной ячейки модели пористой углеродной структуры с размером нанопор $0.2-1.12 \mathrm{~nm}$ в кубический объем размером $3 \times 3 \times 3 \mathrm{~nm}$ помещались хаотично расположенные графеновые чешуйки размером $0.5 \times 0.5 \mathrm{~nm}$. Расположение чешуек осуществлялось с условием, чтобы расстояние между чешуйками было не менее $0.142 \mathrm{~nm}$ (длина химической связи между атомами углерода).

Элементарная ячейка третьей модели стеклоуглерода была сформирована на основе фуллереноподобных частиц $\mathrm{C}_{296}$ и $\mathrm{C}_{600}$, замкнутой графеновой ленты и фрагмента углеродной нанотрубки.

Для всех трех структур указывались периодические граничные условия. Процесс минимизации полной энергии структур осуществлялся с использованием молекулярно-механического метода на основе потенциала Бреннера. В процессе минимизации учитывалась перестройка химических связей между атомами углерода. При этом наблюдалось образование пористой структуры, что подтверждается наличием $s p^{2}-$ и $s p^{3}$-гибридизации у пористых углеродных материалов.

Полученные нами размеры нанопор и значения модуля Юнга пористых углеродных наноструктур с одинаковой плотностью $1.4 \mathrm{~g} / \mathrm{cm}^{3}$ представлены в таблице. Исходя из данных таблицы можно сделать вывод, что чем меньше размер пор в пористой углеродной структуре, тем она более жесткая. Данный результат согласуется с результатами работы [13], в которой механические свойства пористых структур исследовались методом конечных элементов.

\section{4. Заключение}

С помощью методов компьютерного моделирования в работе впервые проведено теоретическое исследование модуля Юнга пористых углеродных наноструктур с плотностью $1.4 \mathrm{~g} / \mathrm{cm}^{3}$ в зависимости от размера пор.

Установлено, что модуль Юнга пористых углеродных наноструктур с плотностью $1.4 \mathrm{~g} / \mathrm{cm}^{3}$ при разном размере нанопор имеет следующие значения: для нанопор $0.4-0.8 \mathrm{~nm}$ он составляет $\sim 1.49 \mathrm{TPa}$, для нанопор $0.2-1.12 \mathrm{~nm} \sim 732 \mathrm{GPa}$, а для нанопор $0.7-1.3 \mathrm{~nm}$ $\sim 661 \mathrm{GPa}$.

Результаты прогностического моделирования показали, что модуль Юнга пористых углеродных наноструктур изменяется в сторону уменьшения с увеличением пористости структуры.

В связи с тем что стеклоуглерод является пористой углеродной структурой с плотностью $1.4 \mathrm{~g} / \mathrm{cm}^{3}$ [7-11], управлять его механическими свойствами можно за счет изменения размеров нанопор. Следовательно, значения модуля Юнга $30 \mathrm{GPa}$ для получаемого в эксперименте стеклоуглерода можно достичь при размере нанопор 15-20 nm, как показано в работе [14], а для других значений нанопор при той же плотности материала модуль Юнга будет изменяться.

Можно предположить, что исследуемые в работе пористые наноструктуры могут быть перспективными материалами для сорбентов, а также для наноэмиттеров и наноэлектромеханических устройств.

\section{Список литературы}

[1] M. Xing, B. Li, Z. Yu, Q. Chen. Materials 9, 484 (2016).

[2] W. Yang, S. Mao, J. Yang, T. Shang, H. Song, J. Mabon, W. Swiech, J.R. Vance, Z. Yue, S.J. Dillon, H. Xu, B. Xu. Sci. Rep. 6, 24187 (2016).

[3] M. Iwaki. Surface Coatings Technol. 158, 377 (2002).

[4] C.Y. He, L.Z. Sun, C.X. Zhang, J.X. Zhong. Phys. Chem. Chem. Phys. 15, 680 (2013).

[5] C.Y. He, L.Z. Sun, C.X. Zhang, X.Y. Peng, K.W. Zhang, J.X. Zhong. Phys. Chem. Chem. Phys. 14, 8410 (2012).

[6] Y.A. Kvashnina, A.G. Kvashnin, P.B. Sorokin. J. Appl. Phys. 114, 183708 (2013).

[7] R.E. Franklin. Proc. Roy. Soc. A. 209, 196 (1951).

[8] P.J.F. Harris. Int. Mater. Rev. 42, 206 (1997).

[9] M. Yao, J. Xiao, X. Fan, R. Liu, B. Liu. Appl. Phys. Lett. 104, 021916 (2014).

[10] P.J.F. Harris. J. Mater. Sci. 48, 565 (2013).

[11] H. Liang, X. Ma, Z. Yang, P. Wang, X. Zhang, Z. Ren, M. Xue, G. Chen. Carbon 99, 585 (2016).

[12] А.С. Фиалков. Углеграфитовые материалы. Энергия, М. (1979). 320 c.

[13] K. Shuting. Porous structure modeling with computers. Department of Mechanical Engineering of the University of Hong Kong (2014). 127 p.

[14] Z. Zhao, E.F. Wang, H. Yan, Y. Kono, B. Wen, L. Bai, F. Shi, J. Zhang, C. Kenney-Benson, C. Park, Y. Wang. Nature Commun. 6, 6212 (2015).

[15] C.L. Burket, R. Rajagopalan, A.P. Marencic, K. Dronvajjala, H.C. Foley. Carbon 44, 2957 (2006). 
[16] O.J.A. Schueller, S.T. Brittain, C. Marzolin, G.M. Whitesides. Chem. Mater. 9, 1399 (1997).

[17] B.A. Samuel, M.A. Haque, Y. Bo, R. Rajagopalan, H.C. Foley. Nanotechnology 18, 115704 (2007).

[18] D.W. Brenner Phys. Rev. B 42, 9458 (1990).

[19] О.Е. Глухова, О.А. Терентьев. Программный продукт „Программа для моделирования наноструктур (Ring)“. Свидетельство о государственной регистрации программ для ЭВМ № 2010612881. Зарег. 28.04.2010.

[20] О.Е. Глухова, А.С. Колесникова. ФТТ 53, 1855 (2011).

[21] Ч. Киттель. Введение в физику твердого тела. Наука, М. (1978). $792 \mathrm{c.}$

[22] И.Е. Беринский, Н.Г. Двас, А.М. Кривцов, А.М. Курадова, В.А. Кузьмин, А.А. Ле-Захаров, О.С. Лобода, И.И. Нейгебауэр, Е.А. Подольская. Теоретическая механика. Упругие и тепловые свойства идеальных кристаллов. Политехн. ун-т, СПб. (2009). 143 с. 